Journal of Case Reports 2017;7(1):47-50

\title{
Servelle-Martorell Syndrome
}

\author{
Arvinder Singh \\ Department of Radiodiagnosis, Government Medical College, Amritsar, Punjab, India.
}

\section{Corresponding Author:}

Dr. Arvinder Singh

Email: arvinderdr@rediffmail.com

This is an Open Access article distributed under the terms of the Creative Commons Attribution License (creativecommons.org/ licenses/by/3.0).

Received : November 4, 2016

Accepted : January 18, 2017

Published : February 5, 2017

\begin{abstract}
Background: Servelle-Martorell syndrome is a rare venous malformation rarely involving arterial system and is associated with skeletal abnormalities. Case Report: A 25 year young male presented with progressive enlargement of left upper limb and shoulder girdle since birth. Multiple grotesque, soft, swollen areas were observed over the whole of the arm upto the shoulder girdle. $X$ ray and ultrasound were suggestive of soft tissue swellings with phleboliths in the affected upper limb and periscapular region with hypoplastic distal bones. Color Doppler showed mildly reduced arterial blood flow with normal spectral analysis. A contrast enhanced CT study showed multiple superficial dilated veins calcified intraluminal areas suggestive of phelboliths, hypotrophic muscles, thinning of radius and ulna and normal arterial system. Conclusion: Early diagnosis of the Servelle - Martorell syndrome can help in reducing the morbidity of the patient along with associated complications.
\end{abstract}

Keywords: Arm, Radius, Shoulder, Ulna, Upper Extremity, Vascular Disorders.

\section{Introduction}

Servelle-Martorell syndrome (SMS) is also known as Servelle-Martorell angiodysplasia or phlebectatic osteohypoplastic angiodysplasia is characterized by ectatic aneurysmal dilatation of the superficial venous channels and skeletal abnormalities leading to monstrous deformity of the affected extremity. Pathophysiology involves partial or complete lack of valves in the deep venous system, intra-osseous vascular malformations due to the destruction of spongiosa and cortical bone joint destruction due to intra-osseous vascular ectasias. Plain X-ray may demonstrate multiple soft-tissue swellings, multiple phleboliths in the ectatic venous system and hypoplasia of the bones [1-4].

\section{Case Report}

A 25 year young male presented with an enlarged left upper limb and left shoulder girdle. The left arm had been much larger than the right upper limb since birth and without much pain. The pain and swelling gradually increased with age and became worse when the limb was lowered. The physical examination showed multiple grotesque looking swollen areas in the whole of the arm and shoulder girdle [Fig.1a]. These areas were soft and compressible, with significant reduction in size with elevation. The palm and forearm showed a bluish discoloration. Other parts of the body showed no discoloration. The left arm was slightly shorter than the right and this reduction in length was due to an overall shortening rather than localized shortening.

The peripheral pulses were palpable with equal volume on both sides. The left forearm and hand bones were short stubby in nature without any sensory deficit. No bruits, thrills or any temperature difference was observed. The cardiovascular system was normal. The plain X-ray of left arm showed multiple soft tissue swellings and hypotrophy of the bones of left upper limb, multiple well-defined radio-opaque lesions consistent with phleboliths 
in the affected upper limb and periscapular region [Fig.1b]. Ulna showed slight deformity and hypoplasia.

The musculoskeletal ultrasound showed multiple dilated tortuous anechoic areas involving the left upper limb and periscapular region with echogenic lesions within them suggestive of phleboliths [Fig.2a]. The forearm muscles were thinned out. On the color Doppler study, these tortuous anechoic structures showed partial color filling within them on graded compression [Fig.2b]. Arterial blood flow was mildly reduced. On CECT, multiple dilated veins in the superficial aspect of the left upper limb and shoulder girdle along with calcified intraluminal areas were seen within them suggestive of phleboliths [Fig.3a-d]. The left subclavian, axillary, brachial, proximal radial and ulnar arteries were normal in course and caliber. There was evidence of abnormal irregular tortuous dilatation of the distal interosseus artery just above the wrist joint and was entering into the distal radius bone. The length of the involved segment was about $3.2 \times 2.5 \mathrm{~cm}$. The palmar arch was normally visualized with normal intersegmental and digital arteries.

Multiple discrete rounded to oval calcific foci were seen in the soft tissue planes of the left upper limb in left axillary region in line of deep venous

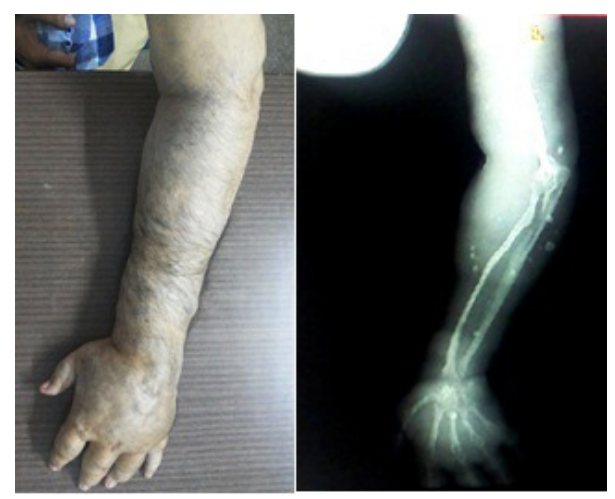

Fig.1(a): Multiple soft tissue swelling involving the entire upper limb, axilla and periscapular region. (b): X-ray left upper limb showing soft-tissue swellings, thinning and dysplasia of the ulna and radius, and multiple well-defined, radio-opaque lesions consistent with phleboliths. channels. The largest lesion measured about 12 $\mathrm{mm}$ in size and these were located primarily in the subcutaneous plane, with a few of them scattered in the deep muscle planes. They appeared to be in relation to the venous channels. Few such foci were also seen in the periscapular region [Fig.3a-d]. The ulna and radius showed hypoplasia, distortion and bowing. Relatively, the humerus showed slightly lengthening [Fig.4a,b]. 3D volume rendering of left upper limb showed irregular soft tissue

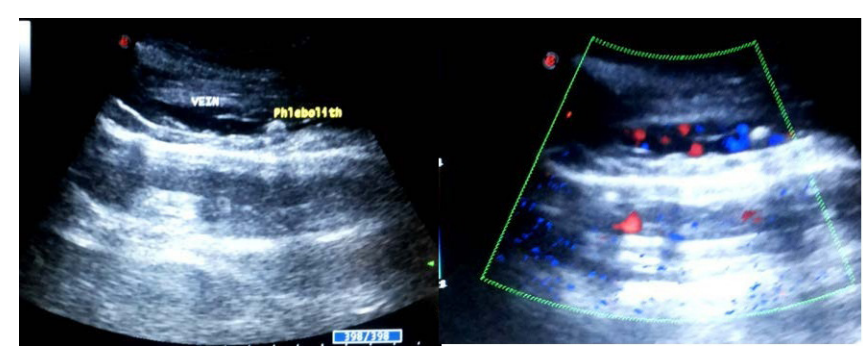

Fig.2(a): Ultrasound using 3.5MHz convex probe showing linear tortuous tubular anechoic structures in the soft tissue of left upper arm suggestive of venous channels. A phlebolith is also seen with its lumen giving posterior acoustic shadowing. No well-formed valves were noted within them. (b): On Color Doppler, minimal scattered filling was noted on graded compression with well display of intraluminal phleboliths.

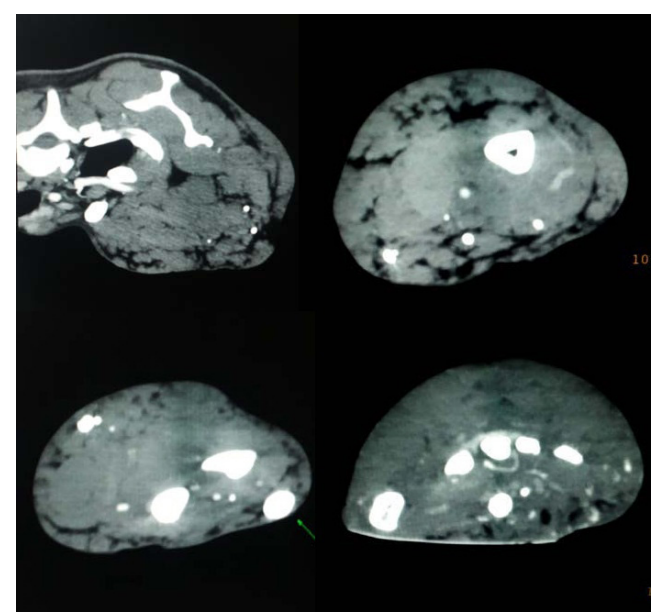

Fig.3(a-d): CECT left arm after intravenous contrast administration showing multiple well defined rounded to oval calcified lesions in line with the superficial and deep venous channels of left arm and shoulder girdle suggestive of intravenous phleboliths (arrow). Note marked swelling of the subcutaneous tissues starting from the shoulder region involving the whole of the left arm and the dorsum of the left hand. 
swellings with limb deformity and short stubby hand [Fig.4c]. Keeping in view the left upper limb soft tissue hypertrophy and skeletal hypoplasia on radiological findings, the diagnosis of ServelleMartorell syndrome was made.

The case was managed conservatively and nonoperatively by external compression with graduated compression stockings to diminish the symptoms of venous insufficiency. No complications like venous thrombosis, coagulopathy, cellulites or recurrent bleeding was reported.

\section{Discussion}

The ectatic and aneurysmal dilatation of the superficial venous channels in Servelle-Martorell syndrome may lead to a monstrous deformity of the extremity $[1,3]$. An abnormal vein location, partial or complete lack of valves, and/or venous hypoplasia or aplasia has been observed in the deep venous system [2,5]. Intra-osseous vascular malformations may lead to bony hypoplasia with the destruction of spongiosa and cortical bone, resulting in limb shortening and joint destruction. The venous malformations vary from isolated cutaneous ectasias to extensive voluminous lesions involving soft tissues and various organs. These lesions are compressible, without any significant change in cutaneous temperature, thrill or bruits and may mimic cavernous hemangiomas. The pure venous malformations are blue in color, while the combined venous malformations and capillaries exhibit a hue that ranges from dark-red to violet with the slow venous flow. The formation of venous thrombosis is quite common and pain may be felt at the site of the thrombus. Coagulopathy may be taken into consideration in cases of invasive procedures in such cases. The prognosis of this disorder is uncertain.

Adequate radiological investigations like a plain X-ray, high resolution sonography, color Doppler studies with graded compressive techniques, computed tomography are utilized

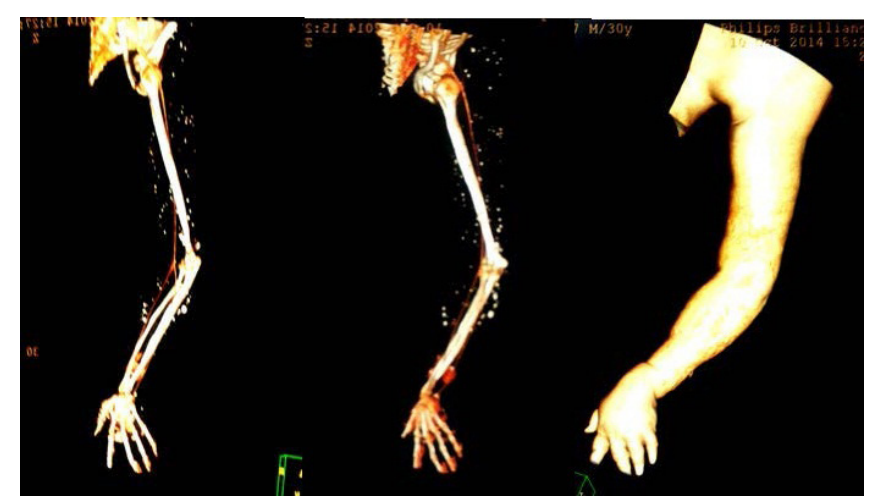

Fig.4(a-b): CT angiography showing outline of the arterial system of the left upper limb. Multiple discrete calcified foci are seen in the soft tissue of the arm suggestive of phleboliths. The humerus is slightly lengthened, the ulna and radius are hypoplastic and deformed in nature as seen in bony algorithm. (c): showing $3 D$ volume rendering images of same patient showing shortening and deformed forearm with irregular soft tissue swellings up to the dorsum of the hand.

for diagnosis, however, MRI is the best imaging method for diagnosis with corroborative clinical findings. Other similar conditions such as KlippelTrenaunay, Parkes-Weber and Blue rubber bleb nevus syndromes can also present with limb and bone hypertrophy.

Therapy is predominantly conservative. In the presence of aneurysms complications or severe shunting, surgery may be indicated. Unilateral upper limb Servelle-Martorell syndrome has been reported rarely in the literature $[5,6]$.

\section{Conclusion}

Servelle-Martorell syndrome with such extensive unilateral limb involvement is an uncommon entity. Many of these patients may be labeled as cases of Klippel Trenaunay syndrome, ParkesWeber and Blue rubber bleb nevus syndromes. However a detailed history, clinical examination and basic imaging investigations help in reaching the diagnosis of this syndrome. Early diagnosis of the Servelle-Martorell syndrome helps in reducing the morbidity of the patient along with associated complications. 
Contributors: AS wrote the mansucript, did literature search, radiodiagnostic imaging and diagnosis. Funding: None; Competing interests: None stated.

\section{References}

1. Karuppal R, Raman RV, Valsalan BP, Gopakumar TS, Kumaran CM, Vasu CK. Servelle-Martorell syndrome with extensive upper limb involvement: a case report. Journal of Medical Case Reports. 2008;2:142.

2. Enjolras O, Mulliken JB. Vascular malformations. In: Textbook of Pediatric Dermatology, Oxford: Blackwell Science;2000:975-996.
3. Langer M, Langer R. Radiologic aspects of the congenital arteriovenous malformations, Klippel-Trenaunay type and Servelle-Martorell type. Rofo. 1982;136:577-582.

4. Weiss T, Madler U, Oberwittler H, Kahle B, Weiss C, Kubler W. Peripheral vascular malformation (ServelleMartorell). Circulation. 2000;101(7):82-83.

5. Legiehn GM, Heran MKS. Classification, Diagnosis, and Interventional Radiologic Management of Vascular Malformations. Orthop Clin N Am. 2006;37:435-474.

6. Angel C, Yngve D, Murillo C, Hendrick E, Adegboyega P, Swischuk L. Surgical treatment of vascular malformations of the extremities in children and adolescents. Pediatr Surg Int. 2002;18:213-217. 